\title{
GESTÃO DA AMPLIAÇÃO DO ENSINO FUNDAMENTAL DE NOVE ANOS: MOVIMENTOS HISTÓRICO-OFICIAIS E NO CAMPO DA PESQUISA
}

\author{
MANAGEMENT OF EXTENSION OF NINE YEARS OF BASIC EDUCATION: \\ HISTORICAL AND OFFICERS AND MOVES IN THE FIELD OF RESEARCH
}

\section{GESTIÓN DE LA AMPLIACIÓN DE LA ENSEÑANZA FUNDAMENTAL DE NUEVE AÑOS: MOVIMIENTOS HISTÓRICO-OFICIALES Y EN EL CAMPO DE LA INVESTIGACIÓN}

Rosilene Lagares*

\begin{abstract}
Resumo: Neste artigo, construído por meio de revisão bibliográfica e documental, cujo tom pretende-se construtivo, descrevemos e examinamos informações histórico-oficiais para a constituição da ampliação do Ensino Fundamental para nove anos, a partir das normas e dos documentos orientadores do final dos anos 1990, com o objetivo de produzir um histórico formal da ampliação. Discutimos ideias de pesquisadores que atuam no interior desse processo, com ênfase na gestão da ampliação. Isso é feito de modo a contribuir com outras configurações e contornos acerca desse nível de ensino, com a política de ampliação sob a ótica da efetivação do direito à educação de qualidade para todas as pessoas em todos os municípios brasileiros. As normas são consideradas instrumento significativo para a compreensão da política, do planejamento e da gestão educacional, mas sem atribuir-lhe valor extremado, desconsiderando, por exemplo, aspectos culturais, de implantação, financiamento, acompanhamento e avaliação de políticas públicas. Destacamos contradições no interior das próprias orientações, com as excepcionalidades e os impasses do processo de ampliação, a despeito da existência de várias normas e diretrizes nacionais. Discutimos a ausência da gestão democrática no processo de ampliação, concebida como espaços e modos de ouvir, debater, convencer ou chegar a consensos, admitindo e incorporando a diversidade de controle social e popular e não só de consulta popular ou de interlocução com o Estado, bem como a ausência ou os desencontros de orientações, que comprometem possíveis propósitos democráticos dessa política. Enfatizamos alguns desafios ainda presentes na constituição de um novo Ensino Fundamental. Por fim, apontamos a não democratização do Ensino Fundamental; a necessidade emergencial de acompanhamento, monitoramento e avaliação específicos da implementação desse nível de ensino junto aos municípios brasileiros, especialmente os mais pobres. E insistimos que a democratização das informações e do debate ainda constitui um desafio.
\end{abstract}

Palavras-chave: Direito educacional. Política e gestão da educação. Direito à educação. Educação em territórios municipais.

Abstract: This article, whose tone is intended to be constructive through the review of literature
and documents, describes and examines historical official information to constitute the expansion of
Elementary School to nine years, based on guidelines and documents from the late 1990s, aiming at
producing a formal history of the expansion. We discuss ideas of researchers within this process, with

* Doutora em educação pela Universidade Federal de Goiás. Professora do Programa de Pós-Graduação em Educação da Universidade Federal do Tocantins. Correio eletrônico: lagaresrose@gmail.com. 
emphasis on management of the expansion. This is done in order to contribute with other configurations and contours on this level of education, with the policy of expanding, under the perspective of making effective the right to qualified education to all people in every Brazilian municipality. Guidelines are considered a significant tool to understanding educational policies, planning and management, but without giving it excessive value, disregarding, for example, cultural aspects, and others of implementation, financing, monitoring and evaluation of public policies. We highlight contradictions in the guidelines, with exceptionalities and impasses of the expansion process, despite the existence of several national standards and guidelines. We discuss the lack of a democratic management in the process of expansion, conceived as spaces and modes of listening, debating, convince or achieving a consensus, admitting and incorporating the diversity of social and popular control, and not only popular consultation or dialogue with the State, as well as the absence of guidelines that compromise possible democratic purposes of this policy. We emphasize some challenges still present in the formation of a new Elementary School. Finally, we point out the non-democratization of Elementary School; the emergent need for monitoring, tracking and evaluating the implementation of this level of school along the Brazilian municipalities, especially the poorest. And we insist that the democratization of information and debates is still a challenge.

Keywords: Educational law. Educational policy and management. Right to education. Education in municipalities.

Resumen: En este artículo, construido mediante una revisión bibliográfica y documental, y cuyo tono pretende ser constructivo, describimos y examinamos las informaciones histórico-oficiales para la constitución de la ampliación de la Enseñanza Primaria para la duración de nueve años, a partir de las normas y de los documentos orientadores de fines de los años 1990, con el objetivo de producir un histórico formal de la ampliación. Discutimos las ideas de los investigadores que actúan en el interior de este proceso, con énfasis en la gestión de la ampliación. Ello se hace de modo a contribuir con otras configuraciones y perfiles acerca de este nivel de enseñanza, con la política de ampliación bajo la perspectiva de la efectividad del derecho a la educación de calidad para todas las personas en todos los municipios brasileños. Se consideran las normas un instrumento significativo para la comprensión de la política, de la planificación y de la gestión educacional, pero sin otorgarle un valor extremado, desconsiderándose, por ejemplo, aspectos culturales, de implantación, financiación, supervisión y evaluación de políticas públicas. Subrayamos contradicciones en el interior de las propias orientaciones, con las excepcionalidades y los puntos críticos del proceso de ampliación, a pesar de la existencia de varias normas y directrices nacionales. Discutimos la ausencia de una gestión democrática en el proceso de ampliación, concebida como espacios y modos de oír, debatir, convencer o llegar a consensos, admitiendo e incorporando la diversidad de controle social y popular y no sólo de consulta popular o de interlocución con el Estado, así como también la ausencia o los desencuentros de orientaciones, que comprometen posibles propósitos democráticos de esta política. Enfatizamos algunos retos todavía presentes en la constitución de una nueva Enseñanza Primaria. Por último, señalamos la no democratización de la Enseñanza Primaria; la necesidad apremiante de supervisión, monitorización y evaluación específicos de la implementación de este nivel de enseñanza junto a los municipios brasileños, especialmente los más pobres. E insistimos que la democratización de las informaciones y del debate todavía constituye un reto.

Palabras clave: Derecho educacional. Política y gestión de la educación. Derecho a la educación. Educación en territorios municipales. 


\section{Introdução}

O nível de escolarização denominado como fundamental (Brasil, 1988) - das normas, políticas e planejamentos restritos a alguns sistemas de ensino até a política nacional de ampliação da duração para nove anos - presenciou momentos e movimentos diversos, recebeu nomenclaturas distintas e passou por várias formas de organização.

Do ensino de primeiras letras, passou a instrução primária, ensino primário e ensino de primeiro grau; com a escolaridade gratuita e não obrigatória passando à escolaridade obrigatória e gratuita de oitos anos.

Do ensino de primeiro grau, passou a Ensino Fundamental, com a extensão da escolaridade obrigatória e gratuita de oitos anos ao direito público subjetivo, com mudanças em sua essência e a política de focalização.

Da duração de oito anos, passou ao Ensino Fundamental de nove anos, com o ciclo da infância, juntamente com a ampliação da obrigatoriedade da educação brasileira para além do Ensino Fundamental, mas ainda com foco no público de 6 a 8 anos de idade (com o Pacto pela Alfabetização na Idade Certa).

De oferta restrita aos cidadãos da colônia, passou a direito público subjetivo e com oferta regular, sendo o não oferecimento uma responsabilidade da autoridade competente. Nesta segunda década do século XXI, é o nível de ensino a que todo cidadão tem o direito e o dever de acesso, permanência e aprendizagem, com tempos, espaços e conteúdos de aprendizagem em tempo integral.

A partir de 2005, em âmbito nacional, o poder público passou a ter o dever de oferecer e garantir a permanência e o desenvolvimento na escola de Ensino Fundamental dos alunos a partir de 6 anos de idade.
Os reflexos de tal alteração foram sentidos diretamente pelas administrações públicas estaduais e municipais, as quais passaram a ter a incumbência constitucional de atender ao Ensino Fundamental.

Dentre os reflexos dessa mudança está a responsabilidade em arcar com o aumento de despesas decorrentes das modificações normativas impostas, pressupondo-se, por exemplo, novas turmas, mais material didático - em quantidade suficiente e adequada aos novos alunos -, disponibilidade de espaços físicos e profissionais em número suficiente e preparados.

A partir desses movimentos no processo de constituição do Ensino Fundamental de nove anos, o debate ganhou espaço e houve algumas conquistas. Entretanto, ainda é preciso ampliá-lo, sabendo que é assunto polêmico e com posições divergentes, pois toda a população tem o direito a esse nível de escolarização, com qualidade e garantias de aprendizagem. Estamos, então, debatendo um direito.

Neste artigo, cujo tom pretende-se construtivo, descrevemos e examinamos informações histórico-oficiais para a constituição da ampliação do Ensino Fundamental para nove anos, a partir das normas e dos documentos orientadores do final dos anos 1990, com o objetivo de produzir um histórico formal da ampliação. Além disso, discutimos resultados de pesquisas acerca do interior desse processo.

O procedimento metodológico adotado foi a revisão de literatura e de aparato documental, tendo como referência pesquisas, normas educacionais nacionais, fontes documentais elaboradas pelo Conselho Nacional de Educação / Câmara de Educação Básica, pelo Ministério da Educação e por órgãos oficiais nacionais que definem as políticas públicas de educação. 
Vieira e Albuquerque (2002, p.28) argumentam que "o aprofundamento de uma análise da dinâmica entre o planejamento, a política e a legislação educacional permite constatar que podem ocorrer combinações inusitadas, como políticas sem planejamento, legislação sem política, planejamento sem legislação.” Assim, no caso em estudo, o número expressivo de normas e orientações acerca do Ensino Fundamental de nove anos pode resultar ou não em políticas, planejamentos e gestões efetivos.

Com base nesses procedimentos, organizamos o artigo em duas seções, seguidas de algumas considerações finais.

Na primeira seção, descrevemos movimentos histórico-oficiais dos processos de constituição do Ensino Fundamental de nove anos, com suas disposições, justificativas e significados, sublinhando os principais argumentos das normas e diretrizes para essa política. Também abordamos o ciclo da infância e o ciclo de alfabetização na constituição do Ensino Fundamental de nove anos. Em seguida, apresentamos uma revisão de literatura, discutindo aspectos da gestão do processo de ampliação desse nível de ensino para nove anos. Por fim, enfatizamos alguns desafios que ainda estão presentes no caminho para a constituição de um novo Ensino Fundamental.

\section{Processos de constituição do Ensino Fundamental de nove anos: movimen- tos histórico-oficiais}

A ampliação da duração do Ensino Fundamental para nove anos é justificada e entendida de diferentes formas.

Para o Ministério da Educação, que compreende essa política como "uma medida contextualizada nas políticas educacionais focalizadas no Ensino Fundamental"
(BRASIL, 2004a, p.19), a ampliação objetiva que todas as crianças de 6 anos, "sem distinção de classe” (BRASIL, 2004b, p.2), sejam matriculadas na escola.

Essa atitude também permitirá aumentar o número de crianças incluídas no sistema educacional, sendo que "Os setores populares deverão ser os mais beneficiados, uma vez que as crianças de 6 anos da classe média e alta já se encontram majoritariamente incorporadas ao sistema de ensino." (BRASIL, 2004a, p.19).

O referido documento alerta para o fato de que a inclusão de crianças de 6 anos não deverá significar a antecipação dos conteúdos e atividades que tradicionalmente foram compreendidos como adequados à primeira série do Ensino Fundamental de oito anos. Destaca, portanto, a necessidade de se construir uma nova estrutura e uma nova organização dos conteúdos, agora prevendo um Ensino Fundamental de nove anos (BRASIL, 2004a).

Em síntese, para o Ministério da Educação (BRASIL, 2009c), os objetivos da ampliação são:

- melhorar as condições de equidade e de qualidade da Educação Básica;

- estruturar um novo Ensino Fundamental, para que as crianças prossigam nos estudos, alcançando maior nível de escolaridade;

- assegurar que, ingressando mais cedo no sistema de ensino, as crianças tenham mais tempo para as aprendizagens da alfabetização e do letramento.

O Conselho Nacional de Educação/ Câmara de Educação Básica (BRASIL, 2010a), ao tratar das diretrizes curriculares nacionais para o Ensino Fundamental de 
nove anos, enfatiza o direito à educação, entendido como um direito inalienável do ser humano. Esse nível de ensino deve estar comprometido com uma educação com qualidade social.

\section{Normas e diretrizes para a política de ampliação: mais de uma década de debates e orientações}

\section{Constituição e leis nacionais no campo da educação}

Após o fervor da política de focalização no Ensino Fundamental nos anos 1990, outro momento marcante para o processo de constituição desse nível de ensino no Brasil é a instituição da política de ampliação de sua duração - cujo princípio da ampliação dos tempos escolares encontra-se na Lei de Diretrizes e Bases da Educação Nacional n.9.394/96 (BRASIL, 1996), seja em horas diárias (art. 34 e 87), seja em anos (art. 32), instigando discussões em nível nacional e a sistematização de vários documentos tratando da ampliação do Ensino Fundamental para nove anos, em regime de cooperação (art. 87).

Nos anos 2000, com o Plano Nacional de Educação (BRASIL, 2001), a ampliação torna-se meta da educação nacional, considerando-se que o plano reforça o princípio da ampliação dos tempos escolares, aborda a duração da Educação Infantil até os 5 anos de idade, explicita o princípio da ampliação do Ensino Fundamental para nove anos de duração e trata da ampliação de horas diárias de aula até o turno integral.

Em maio de 2005, a Lei n.11.114 (BRASIL, 2005a) torna obrigatório o início do Ensino Fundamental aos 6 anos de idade e dispõe sobre o dever dos pais ou responsáveis com essa matrícula (art. $6^{\circ}$ ). No entanto, mantém a duração desse nível de ensino com o mínimo de oito anos (art. 32), abrindo precedente para a conclusão da Educação Básica um ano mais cedo.

Por isso, em fevereiro de 2006, a Lei n.11.274 (BRASIL, 2006a) explicita obrigatoriedade da duração da Educação Infantil até os 5 anos de idade e do Ensino Fundamental com a duração de nove anos, com matrícula obrigatória a partir dos 6 anos.

Em dezembro de 2006, a Emenda Constitucional (EC) n.53 (BRASIL, 2006b) altera a faixa etária coberta pela Educação Infantil, agora para crianças de até 5 anos. Entretanto, essa medida não elimina os impasses práticos relacionados à idade de matrícula no Ensino Fundamental.

Em novembro de 2009, a EC n.59 (BRASIL, 2009a) amplia a obrigatoriedade do ensino brasileiro para o público entre 4 e 17 anos, retirando o foco legal do Ensino Fundamental. No entanto, posteriormente, outras medidas redirecionariam esse foco aos seus três primeiros anos.

As metas dois e cinco do Projeto de Lei de Plano Nacional de Educação n.8.035/10 (BRASIL, 2010b) tratam diretamente do Ensino Fundamental regular, referindo-se aos aspectos universalização, conclusão na idade correta e alfabetização até os 8 anos de idade.

Apenas em abril de 2013, a Lei de Diretrizes e Bases da Educação Nacional (BRASIL, 1996) é alterada, por meio da Lei n.12.796 (BRASIL, 2013a), para tratar da ampliação do ensino obrigatório no país, reafirmando o acesso à Educação Básica obrigatória como direito público subjetivo.

\section{Conselho Nacional de Educação/Câma- ra de Educação Básica}

Há algum tempo, o Conselho Nacional de Educação/Câmara de Educação Básica vem 
discutindo tal ampliação e suas especificidades, e, com o objetivo de orientar e normatizar esse processo, tem expedido vários atos.

Em 1998, no Parecer CNE/CEB n.20 (BRASIL, 1998), o relator João Antônio Cabral de Monlevade responde à consulta do Instituto Nacional de Estudos e Pesquisas Educacionais acerca da iniciativa da prefeitura de Porto Velho (RO) de estender esse nível de ensino. Sob o argumento de gravidade das repercussões político-educacionais e financeiras da extensão, o Conselho institui um Grupo de Trabalho (GT) para se pronunciar a respeito da duração do Ensino Fundamental. O objetivo do GT seria "orientar os sistemas estaduais e municipais de ensino, em termos de normatização, e Estados e Municípios no sentido da execução política do dever do Estado quanto à Educação Básica e à oferta do ensino obrigatório”.

Dos estudos do GT (BRASIL, 1988), resultam algumas orientações para esse processo. Dentre elas, destacamos:

- a liberdade de ensino;

- o regime de colaboração;

- a preservação ou mesmo o aumento da qualidade do ensino;

- a preservação da identidade pedagógica da Educação Infantil;

- proposta pedagógica para a nova situação;

- a eliminação das classes de alfabetização;

- a inclusão da Educação Especial;

- a avaliação do Fundo de Manutenção e Desenvolvimento do Ensino Fundamental e Valorização do Magistério (Fundef);

- o ajuste do custo aluno-qualidade, de forma a garantir um valor por aluno correspondente a um padrão mínimo de qualidade de ensino.

Já nos anos 2000, especificamente em 2004, o Parecer CNE/CEB n.24 (BRASIL, 2004c), sob a relatoria de Murílio de Avellar Hingel, originário de interesse do Ministério da Educação e do próprio Conselho Nacional de Educação, sistematiza estudos e, visando ao estabelecimento de normas nacionais para a ampliação, destaca alguns pontos:

- a autonomia dos sistemas de ensino para adotar uma ou mais opções com vistas à educação de melhor qualidade;

- a necessidade de reflexão e estudos por parte dos sistemas;

- a democratização do debate envolvendo todos os segmentos interessados antes de optar-se pela alternativa julgada mais adequada à realidade;

- a regulamentação dos programas e projetos dos sistemas por seus respectivos conselhos;

- a articulação entre as secretarias e os conselhos de educação para a validação de suas escolhas;

- o regime de colaboração;

- a universalização no Ensino Fundamental, com a matrícula da criança entre 7 a 14 anos de idade;

- a garantia da oferta e da qualidade da Educação Infantil;

- a preservação da identidade pedagógica da Educação Infantil;

- proposta pedagógica apropriada à faixa etária dos 6 anos;

- a fixação de condições para a matrícula de crianças de 6 anos quanto à idade cronológica;

- a liberdade da iniciativa privada. 
Em 2005, são produzidos dois pareceres, uma indicação e uma resolução:

- Parecer n.6 (BRASIL, 2005b), reexaminando o Parecer n.24/2004, sob a relatoria de Murílio de Avellar Hingel, Maria Beatriz Luce e Arthur Fonseca Filho;

- Parecer n.18 (BRASIL, 2005c), de interesse do próprio Conselho, sob a relatoria de Cesar Callegari, Adeum Hilário Sauer, Arthur Fonseca Filho, Francisca Novantino Pinto de Ângelo, Francisco Aparecido Cordão, Kuno Paulo Rhoden, Maria Beatriz Luce e Murílio de Avellar Hingel;

- Indicação n. 3 (BRASIL, 2005d), também de interesse do Conselho, sob a relatoria de Francisco Aparecido Cordão;

- Resolução n. 3 (BRASIL, 2005e).

Nesses documentos, são abordados aspectos variados da/para a ampliação:

- a implementação do Ensino Fundamental de nove anos como um direito público subjetivo;

- a decisão quanto à primeira série se destinar ou não à alfabetização;

- a prioridade da rede pública em assegurar a universalização da matrícula na faixa etária dos 7 aos 14 anos;

- a consideração dos impactos da ampliação no momento da avaliação da Educação Básica;

- a readequação contábil para o censo escolar;

- a adoção de uma nova nomenclatura geral para o Ensino Fundamental de nove anos de duração: anos iniciais $\left(1^{\circ}\right.$ ao $5^{\circ}$ ano) e anos finais ( $6^{\circ}$ ao $9^{\circ}$ ano);

- a aplicação dos princípios da ampliação às escolas criadas e mantidas pela iniciativa privada;

- orientações para a matrícula das crianças de 6 anos de idade nas redes públicas;

- a garantia de pelo menos nove anos de estudo no Ensino Fundamental;

- a administração da convivência dos dois projetos de Ensino Fundamental no período de transição;

- a consideração da organização federativa e do regime de colaboração em sua regulamentação;

- a necessidade de recenseamento e chamada escolar pública;

- a consideração do ano letivo de 2006 como período de transição;

- a possibilidade de adaptações dos critérios usuais de matrícula dos sistemas de ensino;

- a oferta e a qualidade da Educação Infantil em instituições públicas com a preservação de sua identidade pedagógica;

- a promoção de debates e entendimentos de forma criteriosa e com base em estudos pelos sistemas de ensino;

- a adequação do projeto pedagógico;

- o atendimento das necessidades e a garantia de carreira profissional;

- a revisão das Diretrizes Curriculares Nacionais para a Educação Infantil e para o Ensino Fundamental;

- a definição de normas nacionais para a ampliação.

Em 2006, o Conselho/CEB constrói mais três pareceres, todos sob a relatoria de Murílio de Avellar Hingel:

Olhar de professor, Ponta Grossa, 16(1): 75-97, 2013. Disponível em <http://www.uepg.br/olhardeprofessor> 
- n.39 (BRASIL, 2006c), de interesse do Movimento Interfórum de Educação Infantil do Brasil;

- n.41 (BRASIL, 2006d), de interesse da União dos Dirigentes Municipais de Educação do Rio Grande do Sul;

- n.45 (BRASIL, 2006e), de interesse do Conselho Municipal de Educação de Jataí-Goiás.

Nesses documentos, são ratificadas e explicitadas algumas orientações da/para a política de ampliação:

- a idade cronológica de 6 anos para o ingresso no primeiro ano;

- o direito da criança de ser criança;

- o direito da criança à Educação Infantil;

- a necessidade de tratamento apropriado no caso do ingresso de sujeitos que não tenham experiências com instituições formais de educação já no Ensino Fundamental;

- a matrícula de crianças de 6 anos de idade no Ensino Fundamental supõe, necessariamente, a ampliação de sua duração, não sendo, portanto, admissível uma matrícula que mantenha sua duração em oito anos;

- o direito público subjetivo do cidadão e o dever assumido pelo Poder Público com relação à ampliação;

- a forma de trabalhar nos anos iniciais do Ensino Fundamental, explicitando a perspectiva do tratamento interdisciplinar dos conteúdos e indicando a atuação de um único professor (com formação específica).

Em 2007, mais três pareceres são publicados pelo Conselho Nacional de Educação:
- n.5 (BRASIL, 2007a), sob a relatoria de Murílio de Avellar Hingel, respondendo ao Fórum Estadual dos Conselhos Municipais de Educação do Rio Grande do Sul;

- n.7 (BRASIL, 2007b), reexaminando o Parecer n.5, de interesse do Fórum Estadual dos Conselhos Municipais de Educação do Rio Grande do Sul também do relator Murílio de Avellar Hingel;

- n.21 (BRASIL, 2007c), da relatora Regina Vinhaes Gracindo, que esclarece questões da Secretaria Municipal de Educação de Costa Rica (MS).

O Conselho alerta para o fato de que nas consultas há mais discussões de questões secundárias que de aspectos pedagógicos da ampliação (BRASIL, 2007a) e, mais uma vez, explicita aspectos já tratados em documentos anteriores:

- sobre a convivência de planos curriculares distintos para o Ensino Fundamental;

- a coexistência, no período de transição, do Ensino Fundamental de oito anos, em processo de extinção, e o de nove anos, em processo de implantação e implementação progressivas;

- a idade cronológica para o ingresso no Ensino Fundamental de nove anos;

- o impedimento da matricula de crianças no segundo ano letivo, tendo ou não frequentado a pré-escola;

- a indesejável descontinuidade de atendimento e desenvolvimento de crianças que não atendem à idade cronológica para ingressar no primeiro ano;

- a autonomia dos sistemas de ensino quanto à ampliação; 
- a possibilidade de organização do Ensino Fundamental também em ciclos didáticos e pedagógicos;

- a necessidade de um novo projeto político-pedagógico para o Ensino Fundamental de nove anos;

- a existência de princípios comuns para a iniciativa privada.

Em 2008, no Parecer CNE/CEB n.4 (BRASIL, 2008a), de interesse do Ministério da Educação, o relator Murílio de Avellar Hingel sistematiza orientações acerca do tratamento pedagógico nos três anos iniciais do Ensino Fundamental, reafirmando princípios e normas e esclarecendo aspectos que ainda demarcavam controvérsias ou inadequações dos procedimentos pedagógicos.

Essas orientações reafirmam que a proposta é de um novo Ensino Fundamental - portanto, exigindo um projeto político-pedagógico próprio para crianças cuja matrícula é obrigatória a partir dos 6 anos completos ou a completar até o início do ano letivo, em todos os sistemas de ensino, com implantação até o ano letivo de 2010, bem como com a reorganização da Educação Infantil, com identidade assegurada.

O documento esclarece que o primeiro ano do Ensino Fundamental é parte integrante de um ciclo de três anos de duração, sendo um bloco pedagógico ou ciclo sequencial de ensino, e podendo ser denominado "ciclo da infância”. Porém, há a exigência de outros conteúdos de aprendizagem, mesmo quando se opta pelo sistema seriado e não em ciclos. Portanto, esse nível de ensino poderá ser organizado em ciclos, no todo ou em parte.

Os três anos iniciais são importantes para a qualidade da Educação Básica, sendo voltados à alfabetização e ao letramento, ao desenvolvimento das diversas expressões e ao aprendizado das áreas de conhecimento estabelecidas nas Diretrizes Curriculares Nacionais para o Ensino Fundamental. Nesse sentido, concebe-se a alfabetização como um processo que acontecerá nos três anos iniciais do Ensino Fundamental.

Em consequência disso, a avaliação também é um processo que deve observar como princípios essenciais a forma processual, participativa, formativa, cumulativa e diagnóstica e, portanto, redimensionadora da ação pedagógica. Para isso, deverão ser elaborados instrumentos e procedimentos de observação, de acompanhamento contínuo, de registro e de reflexão permanente acerca do processo de ensino e aprendizagem. Nessa proposta, a avaliação também constitui um momento necessário à construção de conhecimentos pelas crianças em processo de alfabetização.

O documento traz alguns esclarecimentos aos profissionais da educação, mostrando que o agrupamento de crianças de 6, 7 e 8 anos deve respeitar rigorosamente a faixa etária, considerando as diferenças individuais e de desenvolvimento.

Os professores desses três anos iniciais devem trabalhar de forma inter e multidisciplinar. Já os professores de áreas específicas, especialmente no caso da Educação Física e de Artes, devem estar preparados para planejar adequadamente o trabalho no que se refere ao desenvolvimento humano, cognitivo e corporal e às habilidades e interesses demonstrados pelos alunos.

Em 2009, explicitando a intenção de tratar da ampliação de modo sistêmico, o Conselho Nacional de Educação fixa as diretrizes curriculares nacionais para a Educação Infantil, com a Resolução n.5/2009 (BRASIL, 2009b).

Em 2010, novamente o CNE/CEB emite mais três documentos sobre a ampliação, agora na forma de Resoluções:

Olhar de professor, Ponta Grossa, 16(1): 75-97, 2013. Disponível em <http://www.uepg.br/olhardeprofessor> 
- n.1/2010 (BRASIL, 2010c);

- n.6 (BRASIL, 2010d);

- n.7 (BRASIL, 2010e).

Na primeira, definem-se diretrizes operacionais para a implantação do Ensino Fundamental de nove anos, explicitando-se a garantia do direito público subjetivo das crianças com 6 anos de idade - com a matrícula e a frequência. Demarca-se também a compreensão acerca do que seja início do ano letivo para a matrícula final no primeiro ano, devendo esta ser efetivada até o dia 31 de março do ano em que ocorrer a matrícula (BRASIL, 2010c).

Na segunda resolução, o Conselho define diretrizes operacionais para a matrícula no Ensino Fundamental de nove anos e na Educação Infantil, ressaltando mais uma vez a garantia do direito público subjetivo das crianças com 6 anos, com a obrigatoriedade da matrícula e da permanência na escola de Ensino Fundamental (BRASIL, 2010d).

Dentre essas diretrizes, o Conselho permite excepcionalidades, por mais de uma vez, às escolas e seus sistemas de ensino, mantendo matrículas de crianças de 5 anos no Ensino Fundamental.

A terceira resolução, a n.7 (BRASIL, 2010e), fixa as diretrizes curriculares nacionais para o Ensino Fundamental de nove anos, a serem incluídas nos projetos político-pedagógicos das escolas, reunindo princípios, fundamentos e procedimentos para orientação das políticas públicas educacionais.

\section{Ministério da Educação/Secretaria de Educação Básica}

O Ministério da Educação/Secretaria de Educação Básica, desde o início dos anos 2000, também tem elaborado documentos com orientações e diretrizes para a ampliação, enfatizando que essa política deve ser vista como um processo, e, portanto, exigindo medidas sistêmicas e contínuas.

Sobressaem os documentos:

- Primeiro Relatório do Programa: ampliação do Ensino Fundamental para nove anos (Brasil, 2004b);

- Orientações Gerais: Ensino Fundamental de nove anos (BRASIL, 2004a);

- Segundo Relatório do Programa: ampliação do Ensino Fundamental para nove anos (BRASIL, 2005f);

- Terceiro Relatório do Programa: ampliação do Ensino Fundamental para nove anos (BRASIL, 2006f);

- Ensino Fundamental de nove anos: orientações para a inclusão da criança de 6 anos de idade (BRASIL, 2006g);

- Indagações sobre currículo (BRASIL, 2008b);

- Ensino Fundamental de nove anos: passo a passo do processo de implantação (BRASIL, 2009c);

- Ensino Fundamental de nove anos: passo a passo do processo de implantação ( $2^{\text {a }}$ edição - setembro de 2009) (BRASIL, 2009d);

- A criança de 6 anos, a linguagem escrita e o Ensino Fundamental de nove anos: orientações para o trabalho com a linguagem escrita em turmas de crianças de 6 anos de idade (BRASIL, 2009e).

Desse conjunto de diretrizes e orientações, destacamos o discurso do planejamento participativo, com a realização de sete encontros regionais, realizados pelo Ministério da Educação em fevereiro de 2004. Segundo 
o documento, seus objetivos foram garantir subsídios, informações, dados e reflexões a respeito da concepção de uma nova estrutura de organização dos conteúdos. Isso ocorreu levando-se em conta o perfil dos alunos da faixa etária entre 6 a 14 anos (BRASIL, 2004b).

Também se destacam algumas ideias agregadas ao discurso da ampliação, como a concepção de educação e escola com qualidade social; o direito à educação e à inclusão; a escola como polo irradiador de cultura e conhecimento; o desenvolvimento do aluno como a principal referência na organização do tempo e do espaço da escola; a nova idade que integra o Ensino Fundamental, com aspectos próprios dessa faixa etária e da fase de desenvolvimento do aluno; os nove anos de trabalho, com a sugestão de uma nomenclatura (anos iniciais e anos finais); a organização do trabalho pedagógico como questão essencial para a ampliação; o desafio do necessário trabalho coletivo; o perfil e a formação do professor do aluno de 6 anos do Ensino Fundamental (BRASIL, 2004a).

Em 2009 (BRASIL, 2009c), o Ministério elenca, entre outras, algumas medidas essenciais à ampliação, com seus respectivos responsáveis: a definição das diretrizes e orientações nacionais para a reorganização do Ensino Fundamental, como atribuição do Conselho Nacional de Educação; a definição das normas e orientações nos sistemas e redes de ensino pelos conselhos estaduais e municipais de educação; a atualização da proposta pedagógica e a elaboração de um plano de implementação do Ensino Fundamental de nove anos pelas secretarias estaduais e municiais de educação; e a responsabilidade de reformulação do regimento escolar por parte da escola.

Da mesma forma que o Conselho Nacional de Educação, o Ministério (BRASIL, 2009c) sistematiza algumas orientações para a ampliação, agregando aspectos como:

- participação das escolas privadas neste processo;

- nomenclatura do novo nível de ensino;

- equivalência entre o Ensino Fundamental de oito e o de nove anos;

- atuação de municípios sem sistema próprio de ensino;

- data de corte para matrícula no primeiro ano;

- organização pedagógica;

- currículo;

- elaboração e/ou reestruturação do projeto pedagógico das escolas;

- avaliação;

- formação dos profissionais da educação.

Especificamente para a orientação pedagógica do trabalho com as crianças no início desse novo ensino, o documento Ensino Fundamental de Nove Anos: Orientações para a inclusão da criança de seis anos de idade (BRASIL, 2006g) aborda aspectos que considera essenciais para a compreensão e a implementação dessa política:

- a infância e sua singularidade;

- a relação fundamental entre a infância na escola e na vida;

- o brincar como um modo de ser e estar no mundo;

- as diversas expressões e o desenvolvimento da criança na escola;

- as crianças de 6 anos e as áreas do conhecimento;

- a alfabetização e o letramento como eixos orientadores da organização do trabalho pedagógico;

Olhar de professor, Ponta Grossa, 16(1): 75-97, 2013. Disponível em <http://www.uepg.br/olhardeprofessor> 
- a relação entre avaliação e aprendizagem na escola;

- possibilidades de modalidades organizativas do trabalho pedagógico.

O documento A crianças de 6 anos, a linguagem escrita e o ensino fundamental de nove anos: orientações para o trabalho com a linguagem escrita em turmas de crianças de seis anos de idade (BRASIL, 2009e) também traz discussões importantes para a orientação pedagógica no início do Ensino Fundamental:

- aprendizagem da linguagem escrita e Ensino Fundamental de nove anos para crianças com menos de 7 anos;

- dimensões da proposta pedagógica para o ensino da linguagem escrita em classes de crianças de 6 anos;

- letramento;

- desenvolvimento das habilidades de leitura e escrita de palavras, frases e textos em sala de aula;

- aquisição do sistema de escrita e o desenvolvimento da consciência fonológica;

- desenho e brincadeira como formas de linguagem a serem exploradas no processo de alfabetização;

- diálogo com práticas pedagógicas de alfabetização e letramento de crianças de 6 anos;

- ouvir, ver, ler histórias como narrativas verbais e visuais em práticas de letramento literário na infância;

- alfabetizar letrando a partir da literatura infantil;

- jogos linguísticos, como brincadeiras com hipóteses para as crianças;

- produção de textos e desenhos em sala de aula; prazer de ler e escrever para aprender.

Nesse conjunto de normas e diretrizes nacionais, tanto do Conselho quanto do Ministério de Educação, há um foco nos anos iniciais do Ensino Fundamental, permitindo-nos pensar que nos anos finais o trabalho continuará o mesmo, apesar da afirmação de que agora temos um novo Ensino Fundamental e da distribuição de responsabilidades entre os demais entes federados e as escolas.

\section{$O$ ciclo da infância e o ciclo de alfa- betização na constituição do Ensino Fundamental de nove anos: política de focalização?}

Na implementação deste novo Ensino Fundamental, sobressaem orientações a respeito do trabalho com as crianças dos três anos iniciais (no ciclo da infância) e discursos e normas para a alfabetização das crianças até os 8 anos de idade (no ciclo da alfabetização), com o Pacto Nacional pela Alfabetização na Idade Certa (BRASIL, 2012a; 2012b). Essas medidas estimulam um olhar mais específico, com vistas a examinar se vivenciamos outro momento ou outra política de focalização.

Para o Conselho Nacional de Educação/Câmara de Educação Básica (BRASIL, 2008a; 2010e), mesmo que o sistema de ensino optar pela organização seriada, haverá a necessidade de considerar os três anos iniciais do Ensino Fundamental como um bloco pedagógico ou ciclo sequencial de ensino. Ciclo ou bloco voltado à alfabetização e ao letramento, ao desenvolvimento das diversas formas de expressão e ao aprendizado das áreas de conhecimento, como Língua Portuguesa, Literatura, Música e demais artes, Educação Física, Matemática, Ciências, História, Geografia. 
Dessa forma, a alfabetização acontece em um processo ao longo dos três anos iniciais (BRASIL, 2008a; 2010e).

Por sua vez, ciclos, séries e outras formas de organização serão compreendidos como tempos e espaços interdependentes e articulados entre si, ao longo dos nove anos de duração do Ensino Fundamental, em progresso contínuo dos alunos no que se refere ao seu desenvolvimento pleno e à aquisição de aprendizagens significativas (BRASIL, 2010e).

Compreendendo que a alfabetização não se restringe ao primeiro ano, o Conselho (BRASIL, 2008a) também demarca sua concepção de avaliação do ensino e da aprendizagem como um momento necessário à construção de conhecimentos pelas crianças no processo de alfabetização. Assim, devendo a avaliação ser assumida como forma processual, participativa, formativa, cumulativa e diagnóstica - portanto, redimensionadora da ação pedagógica, e não uma mera verificação de conhecimentos visando à classificação. Para tanto, é indispensável a elaboração de instrumentos e procedimentos de observação, de acompanhamento contínuo, de registro e de reflexão permanente sobre o processo de ensino e de aprendizagem.

Outra política envolvendo o Ensino Fundamental é o Pacto Nacional pela Alfabetização na Idade Certa, um compromisso formal assumido pelos entes federados com vistas à alfabetização de todas as crianças até os 8 anos de idade, ao final do terceiro ano do Ensino Fundamental (BRASIL, 2012a, 2012b).

Com o pacto, é instituído o ciclo da alfabetização, desenvolvido nos anos iniciais do Ensino Fundamental. Esse ciclo consiste em um período sequencial de três anos, sem interrupções, dedicados à inserção da criança na cultura escolar, à aprendizagem da leitura e da escrita, à ampliação das capacidades de produção e compreensão de textos orais em situações familiares e não familiares e à ampliação do universo de referências culturais dos alunos nas diferentes áreas do conhecimento (BRASIL, 2013b).

Para Arelaro, Jacomini e Klein (2011), a meta do Movimento Todos pela Educação - alfabetizar todas as crianças até os 8 anos em um primeiro momento pode ser entendida como um avanço. Por outro lado, pode ser compreendida como uma desconsideração às necessidades, especificidades e singularidades com as quais cada criança se relaciona com o mundo e se apropria da cultura socialmente produzida, principalmente quando disso decorrem propostas de se iniciar mais cedo o processo formal de alfabetização e letramento.

Neste momento, não é nosso objeto o aprofundamento a respeito do pacto, mas precisamos demarcar que o país pode correr risco com a possibilidade de um compromisso focado (em três anos do Ensino Fundamental) na alfabetização em Língua Portuguesa e no ensino de Matemática, ficando as outras idades e áreas do conhecimento relegadas a outros planos pelas ações de governos para implementação do pacto.

\section{Gestão (democrática?!) do processo de ampliação do Ensino Fundamental para nove anos: pesquisas}

A ampliação do Ensino Fundamental para nove anos já figurava entre os objetivos e metas para esse nível de ensino, dispostos no anexo da Lei n.10.172/2001 - Plano Nacional de Educação (PNE) (BRASIL, 2001), e já era uma medida adotada em muitos municípios brasileiros. Entretanto, instigou e continua estimulando a compreensão de suas especificidades, como, por exemplo, 
de seus fundamentos políticos e filosóficos, seu planejamento e gestão e suas práticas pedagógicas, com entraves, rupturas e/ou continuidades, avanços e ameaças envolvendo a antecipação da escolarização para as crianças de 6 anos de idade.

O ingresso dessas crianças no Ensino Fundamental e a consequente reestruturação da Educação Infantil produziram efeitos nos modos de conceber as duas etapas de educação e ensino e suas práticas. Também reascenderam os debates acerca da qualidade da educação, da garantia do acesso à escola nas etapas iniciais da Educação Básica, de concepções de infância, entre outros.

Com o objetivo de levantar informações a respeito de aspectos relacionados à ampliação, na revisão de literatura identificamos vários autores tratando de forma diferente esse processo, mostrando resultados de pesquisas com pontos de vista diversificados - mas também convergentes.

A partir do conjunto de estudos e informações, um bom ponto de partida é a abordagem dos aspectos da gestão do processo de implantação do Ensino Fundamental de nove anos.

Inicialmente, vale relembrar como se configurava a gestão desse nível de ensino no Brasil antes da ampliação, com o objetivo de apreender em que condições a ampliação se sustentaria.

Para Arelaro (2005), um olhar sobre os dados estatísticos mais gerais contribuiria com a compreensão da realidade educacional brasileira e do histórico elitismo que a sustenta.

Em relação ao Ensino Fundamental, a partir de dados do Instituto Brasileiro de Geografia e Estatística (IBGE) de 2003, a autora apontou o "vertiginoso" processo de municipalização desse nível de ensino, sendo exagerado por alguns Estados, com percentuais acima de $80 \%$. Notam-se: a responsabilidade "indiscutível" das redes municipais de ensino pelas séries iniciais; o processo heterogêneo dessa distribuição entre as regiões; o empenho do governo federal em ampliar positivamente os resultados, sem significar maior gasto ou expansão do Estado; incentivos para a adoção das classes de aceleração; a organização do ensino por meio de ciclos escolares; o investimento dos menores percentuais no período de 1998 a 2002; o aumento do número de alunos por sala de aula, em decorrência do Fundo de Manutenção e Desenvolvimento do Ensino Fundamental e de Valorização do Magistério (Fundef), com a manutenção do mesmo currículo, das mesmas estratégias de ensino e gratificações no salário docente, sem reajustes; o estabelecimento de Parâmetros Curriculares Nacionais (PCNs), constituindo-se na prática em verdadeiros "Guias Curriculares"; a promoção automática, denominada de progressão continuada (ARELARO, 2005, p.1043-48).

Desses resultados, a autora considerou essencial que a reflexão a respeito da gestão do Ensino Fundamental de nove anos tomasse como referência as situações e condições dos municípios brasileiros. Primeiro, por serem responsáveis, em colaboração com o Estado, pelas atribuições desse nível de ensino. E também devido ao fato de "não terem um mesmo padrão de arrecadação de recursos", mas, sim, "um quadro longe dessa situação de equilíbrio financeiro entre as diferentes esferas públicas, e entre cada uma delas" (ARELARO, 2005, p.1044).

Estudos da organização política e social de diferentes países demonstram que, quando o município - na qualidade de esfera pública - depende, como fonte principal de recursos, das transferências federais - no caso do Brasil, o FPM -, não possuindo fonte de recursos próprios mínimos, ele não teria condições de se viabilizar como 
“ente” público autônomo, lembrando que a Constituição Federal de 1988 - e foi a primeira vez na nossa história federativa - estabeleceu o município como esfera pública, politicamente autônoma.

Mas essa fragilidade financeira não se restringia às esferas municipais. Também era uma realidade de boa parte dos Estados. Assim, para Arelaro (2005, p.1044) "não há fórmulas mágicas: tem-se de cobrar dos que ganham mais - pessoas físicas e jurídicas para distribuir para os que ganham menos."

Nesse contexto, a autora argumentou que dificuldades poderiam advir da ampliação, como o recebimento de crianças com 6 anos de idade sem nenhuma experiência com a instituição educacional; a transição entre os dois níveis de educação, como se fossem duas instâncias semelhantes; a simples incorporação do último ano da Educação Infantil ao Ensino Fundamental, sem o reconhecimento de suas distintas naturezas (ARELARO, 2005, p.1047).

Arelaro, sem desconsiderar que número significativo de países europeus trabalha com o ingresso das crianças entre 5 e 6 anos na escola, pergunta: a quem interessaria essa política? Ao perguntar, ela já levanta a hipótese de que o autor da Lei n.11.114/2005 (BRASIL, 2005) "tenha pretendido ampliar a possibilidade de uso dos recursos do Fundef com crianças menores, uma vez que os municípios se encontram em dificuldades para ampliar sua rede de Educação Infantil, sem contar com o aporte deste fundo" (ARELARO, 2005, p. 1047).

Por fim, a autora argumenta que especialistas também garantiram que o PNE responderia a essa necessidade de ampliação dos recursos municipais, e que, portanto, "o atendimento às crianças matriculadas na Educação Infantil passaria a ser realizado 'disfarçado' de Ensino Fundamental. Mas manter-se-iam, nesse $1^{\circ}$ ano de Ensino Fundamental 'antecipado', as premissas e as orientações da Educação Infantil” (ARELARO, 2005, p.1047).

Santos e Vieira (2006, p.779), em pesquisa realizada acerca da ampliação no Estado de Minas Gerais, em 2004 (anterior à política nacional), argumentam que a implementação dessa política torna-se mais complexa, pois o processo de interpretação dos dispositivos legais pelos sujeitos envolvidos "não é unívoco [...], sejam da rede estadual, sejam das redes municipais de ensino, em Minas e em todo o país, onde várias das questões e dúvidas são levantadas, merecendo, além de respostas, reflexão e pesquisa”.

Gorni (2007), em pesquisa realizada em diferentes cidades e regiões do Estado do Paraná com o objetivo de investigar como a política de ampliação chegou às escolas, bem como de que forma essas instituições se prepararam para tal processo, compreende que " [...] numa tentativa de encurtamento de distância entre as intenções e a realidade, a implantação do Ensino Fundamental de nove anos tem sido discutida com diferentes segmentos da sociedade e do sistema educacional desde 2003 [...] A princípio, parece que a lição de casa está sendo realizada" (GORNI, 2007, p.72).

Entretanto, para a pesquisadora, tal proposição pode significar "uma tendência positiva de existência de um movimento de busca de aprimoramento do processo em desenvolvimento" ou "apenas a ocorrência de mais uma ação pontual de cunho político, com vistas a introduzir uma simples mudança estrutural que pouco ou nada vai interferir na qualidade da educação ofertada no Ensino Fundamental” (GORNI, 2007, p.72).

Gorni considera que a maneira como a proposta chega às escolas e nelas é apreendida, analisada e, em decorrência, 
implementada, influencia no alcance das alterações. E, tendo em vista o modo de atuação que predomina no sistema educacional brasileiro no tocante à introdução de inovações, a proposta de ampliação "tanto pode melhorar, como não alterar e até mesmo piorar o desempenho do sistema educacional, caso não receba o tratamento adequado em sua implementação" (GORNI, 2007, p.73).

Para a pesquisadora, se a mudança consistir apenas em uma mudança estrutural, a tendência é que apenas se antecipe em um ano a idade de ingresso no Ensino Fundamental, o que pode significar a supressão de uma etapa de trabalho importante realizada na Educação Infantil. Se o ingresso aos 6 anos for entendido simplesmente como a alteração do tipo de escola que a criança frequenta, de forma que se mantenha inalterado o trabalho que se desenvolve junto aos alunos, a situação provavelmente se manterá (GORNI, 2007, p.73).

$\mathrm{Na}$ realidade pesquisada, a constatação foi que, naquele momento, muito pouco se sabia acerca da proposta de implantação do Ensino Fundamental de nove anos. Também pairavam dúvidas e preocupações a respeito da proposta poder constituir somente mais uma mudança política e estrutural, significando apenas uma antecipação da alfabetização, o que poderia prejudicar as crianças. Nesse sentido, a autora destaca a precocidade da implantação de forma ampla e generalizada, sem as condições ideais de preparação das instituições educacionais e dos professores (GORNI, 2007).

Saveli (2008), com pesquisas no Estado de Mato Grosso, destaca que a antecipação do acesso e da obrigatoriedade de escolarização da criança de 6 anos é uma medida contextualizada nas políticas educacionais de todos os países europeus e da maioria dos países da América Latina e do
Caribe. Argumenta que, em boa parte desses territórios, o início da escolaridade obrigatória ocorre aos 6 ou 5 anos e que, dentre os países que iniciam a educação obrigatória aos 6 anos, alguns consideram o último ano da pré-escola como obrigatório.

A autora não desconsidera o dissenso acerca do recorte da idade de ingresso no Ensino Fundamental de nove anos, posto na literatura e, segundo ela, presente entre dirigentes educacionais ligados a redes públicas municipais de ensino. Ela trata a ampliação como uma política educacional afirmativa, que traz o princípio de inclusão, considerando-a como um avanço no contexto da realidade brasileira, uma vez que garante o direito à educação a todos os indivíduos, independentemente da classe social a que pertençam. Para tanto, explicita a exigência de tratamento político, administrativo, financeiro e pedagógico da ampliação, bem como a necessidade de assegurar-se que o trabalho pedagógico considere a singularidade das ações infantis e sua necessidade de aprender e de brincar (SAVELI, 2008).

Silva (2009) argumenta acerca do descompasso entre a legislação federal e a situação no Estado de Santa Catarina, apontando para os riscos de uma implementação aligeirada do Ensino Fundamental de nove anos, o que exige dos sistemas uma série de ações políticas, pedagógicas e administrativas consistentes e objetivas.

Embora implementada apenas em 2006, a ampliação é tributária da reforma educacional brasileira da década de 1990, cuja indução acontece por meio de acordos firmados pelos governos brasileiros com os organismos multilaterais e com a política de financiamento adotada, reforçando a importância estratégica atribuída ao Ensino Fundamental (SILVA, 2009). A autora também argumenta que o acúmulo de estudos e 
discussões no tocante à municipalização do Ensino Fundamental e da Educação Infantil revela que nem sempre os processos de descentralização das responsabilidades das políticas sociais têm considerado os limites e as possibilidades dos municípios para assumir determinados serviços, o que sinaliza para uma urgente reforma tributária. Com base em um recorte histórico, alerta quanto as possibilidades de que a ampliação se converta em mera ação administrativa, com a priorização dos aspectos quantitativos (SILVA, 2009).

Silva e Scaff (2010), em pesquisa analisando a implantação dessa política nos Estados da Bahia e do Mato Grosso do Sul, argumenta que o principal avanço dessa política é a garantia legal de acesso à escola para todas as crianças que completam 6 anos até o início do ano letivo. Ao contrário de alguns autores, propõem uma análise em que se reconhece o impacto nos padrões de acesso desencadeado pela implantação da Lei n.11.274/2006 (BRASIL, 2006a), mas questiona a eficácia dessa política como solução para a qualidade da educação.

Arelaro, Jacomini e Klein (2011), tratando dos sujeitos e dos caminhos percorridos para a implantação dessa política educacional no Estado de São Paulo, realizaram pesquisa em redes de ensino municipais e estaduais. Com base em informações do documento Ampliação do ensino fundamental para nove anos: relatório do Programa (BRASIL, 2004), as autoras argumentam, diferentemente de outros, que a implementação dessa medida não foi discutida amplamente com a comunidade educacional, nem com a maioria dos municípios brasileiros - principais responsáveis pela Educação Infantil e pelo Ensino Fundamental. Ao contrário, o Ministério da Educação divulgou dados de sete encontros regionais com Estados e municípios para discutir como implementar a ampliação do Ensino Fundamental para nove anos.
A sociedade e os entes estaduais e municipais não foram ouvidos, não debateram, não houve processo de convencimento ou consenso, "admitindo e incorporando a diversidade” (ARELARO; JACOMINI; KLEIN, 2011, p.9).

As autoras argumentam que a discussão a respeito da ampliação da obrigatoriedade do ensino já estava definida em torno do Ensino Fundamental de nove anos, com a matrícula obrigatória aos 6 anos de idade. $\mathrm{Ou}$ seja, sem a menção de intenção ou da possibilidade de tornar obrigatório o último ano da Educação Infantil, em que grande parte das crianças de 6 anos já estava matriculada.

Sem desconsiderar a importância da discussão realizada, argumentam sobre a necessidade de se conhecer em que medida os sistemas de ensino se apropriaram das orientações do Ministério - principalmente das apresentadas no documento Ensino fundamental de nove anos: orientações para a inclusão da criança de seis anos de idade (BRASIL, 2007) - ou se, baseados nessas orientações, construíram suas próprias políticas (ARELARO; JACOMINI; KLEIN, 2011, p.9).

Para as autoras, em termos de representatividade, foi pequena a participação de Estados e municípios e dos professores e comunidade nas discussões presentes no documento de 2004. Da mesma forma, verificaram que houve pouca orientação aos professores para a implementação dessa política, "o que pode levar a uma "pedagogia do fato consumado" que descaracteriza a proposta e compromete a qualidade do ensino oferecida aos alunos de 6 anos" (ARELARO; JACOMINI; KLEIN, 2011, p.11).

Em se tratando da educação das crianças pequenas, Arelaro, Jacomini e Klein também ponderam que, frente às mudanças anunciadas e ao processo de implantação, o

Olhar de professor, Ponta Grossa, 16(1): 75-97, 2013. Disponível em <http://www.uepg.br/olhardeprofessor> 
Ensino Fundamental de nove anos não representa necessariamente um ganho educacional, uma vez que muitas crianças têm sido submetidas a um regime de trabalho escolar incompatível com sua faixa etária.

Ao contrário do argumento de que as crianças de 6 anos trazem para o Ensino Fundamental uma dinâmica educativa mais atrativa às necessidades das crianças de 7 e 8 anos, a rotina da escola de Ensino Fundamental pouco foi alterada para receber esses novos alunos. Não foram os anos seguintes que se modificaram. Ao contrário, foi o novo primeiro ano que perdeu vigor e vivacidade (ARELARO; JACOMINI; KLEIN, 2011).

Essa organização escolar pode sugerir uma tentativa subliminar de acelerar ou reduzir os tempos da infância, uma vez que há crianças entrando no Ensino Fundamental antes de completar 6 anos. Assim, sem uma restrição radical à entrada das crianças de 5 anos no Ensino Fundamental, é possível, de forma inédita, que haja uma pré-escola com tempos mais restritos que dois anos (ARELARO; JACOMINI; KLEIN, 2011).

Koerner (2012), em pesquisa que envolveu as redes pública e privada na maior cidade de Santa Catarina, argumenta que "De um modo geral [...] o professor teve pouco direito à voz durante o processo de implementação do novo formato do Ensino Fundamental”, cujos conteúdos foram repassados aos professores por meio do repasse de documentos pelos órgãos gestores. Assim, "Transparece a ideia de que a ele coube apenas a função de cumprir o que lhe foi determinado".

Com relação à reorganização pedagógica para o atendimento às especificidades do Ensino Fundamental de nove anos, Souza (2012), em pesquisa analisando os Projetos Político Pedagógicos das escolas da rede municipal de Dourados (MS), observa que a implementação dessa política nas instituições ocorreu em meio a ações de planejamento sistematizado e contínuo. Esse planejamento buscou garantir alterações dos aspectos estruturais e materiais didáticos e pedagógicos, mudanças no currículo, desenvolvimento de formação continuada com os profissionais e revisão das práticas avaliativas.

Segundo a pesquisadora, não houve uma reformulação dos Projetos Político Pedagógicos considerando as especificidades do Ensino Fundamental de nove anos, o que permitiria "afirmar que a implementação dessa política no contexto escolar indica um processo inadequado de reorganização pedagógica, o que pode denotar a simplificação do processo, a mera inclusão das crianças de 6 anos" (SOUZA, 2012, p.9).

Sendo a ampliação uma realidade brasileira neste momento, não desconsiderando os entraves envolvendo a antecipação da escolarização, a inclusão de mais um ano para o Ensino Fundamental deve ter o objetivo de garantir contexto de letramento para todo mundo. E, obviamente, é necessário que os anos finais do Ensino Fundamental deem continuidade a esse trabalho, sempre com a perspectiva da educação de qualidade social, evitando-se a fragmentação, a desarticulação e a descontinuidade, em um permanente processo de análise e de avaliação.

\section{Por fim... para outras configurações e contornos}

Dos processos de constituição do Ensino Fundamental de nove anos, do âmbito das pesquisas, descrevemos pontos convergentes e divergentes, destacamos hipóteses, identificamos causas e consequências. Dos movimentos histórico-oficiais, apreendemos 
normas e diretrizes de um período de mais de uma década.

Nesses campos, vemos o destaque de conquistas no Ensino Fundamental, como a quase universalização do acesso, o aumento das taxas de conclusão, o aumento dos anos de escolaridade da população. Por outro lado, vemos enfoques de outras questões, como a baixa qualidade do ensino, o baixo aprendizado dos alunos, a heterogeneidade entre instituições educacionais do mesmo sistema de ensino e na rede pública. Também se notam enfoques de pesquisadores acerca da não democratização do Ensino Fundamental, considerando que os desafios não circundam apenas a exigência da melhoria da escola.

Em relação à ampliação para nove anos, apreendemos projetos filosóficos, políticos, educacionais e sociais divergentes, traduzindo ora políticas e gestões educacionais mais interessadas nas questões econômicas ou estatísticas, ora com foco nas questões pedagógicas ou de melhoria da qualidade de ensino.

Também é explícita a materialização da ampliação de modos distintos entre regiões, intrarregionalmente e entre escolas. Algumas escolas com medidas e ações adequadas às normas e diretrizes do governo federal, outras com apenas algumas adaptações e outras sem nenhuma adaptação.

São destacados impasses acerca da transição do sistema de oito anos para o de nove, da idade para a matrícula no primeiro ano do Ensino Fundamental, da passagem entre a Educação Infantil e o Fundamental, dos conteúdos curriculares do primeiro ano, da descontinuidade entre os anos iniciais e os anos finais.

Também há ideias a respeito da relevância dessa ampliação, mesmo considerando-se ser ela uma importante reivindicação no campo das políticas públicas de educação, no sentido da democratização do direito à educação. Para alguns, a ausência de uma proposta pedagógica adequada pode significar a antecipação do fracasso escolar. O tempo de escolarização em um nível de ensino não pode, por si só, ser considerado o único fator responsável pela qualidade de ensino. Para outros, o acesso à língua escrita a partir de 6 anos é um direito de todas as crianças.

Muitas das disposições e orientações, mesmo sendo enfatizadas em vários documentos, ainda correspondem a problemas na prática pedagógica. Aliás, há contradições no interior das próprias orientações, as chamadas “excepcionalidades”.

Outro aspecto importante é a situação de descentralização administrativa e financeira do Ensino Fundamental, com a redefinição do papel das instâncias municipais, em boa parte sem considerar as especificidades e capacidades territoriais, o que pode gerar situações não favoráveis à garantia de mais tempo, espaços e conteúdos de aprendizagem significativa.

A política de ampliação está eminentemente desintegrada da política de educação infantil e o trabalho pedagógico proposto para o Ensino Fundamental de nove anos não representa uma continuidade do trabalho pedagógico feito com as crianças de $0 \mathrm{a}$ 5 anos de idade.

A legitimidade e a efetividade dessa ampliação exige dos sistemas de ensino instrumentos jurídicos, políticos, econômicos, pedagógicos e administrativos, bem como de acompanhamento e avaliação em todos os níveis da gestão educacional, para que ela não fique restrita a declarações formais, que muitas vezes são desrespeitadas.

Precisam ser repensados os espaços educativos, os materiais didáticos, o mobiliário e os equipamentos, bem como os 
currículos, com seus conteúdos e práticas pedagógicas, para todo o Ensino Fundamental - e não apenas ou mais para os três primeiros anos. A Educação Infantil deve ser redimensionada; a produção normativa deve ser específica para os sistemas de ensino; devem ser consultadas outras fontes (pesquisas educacionais e literatura pertinente, com análises, relatos de experiências e alternativas); deve ser respeitada a idade correta para o ingresso no primeiro anos; por fim, a avaliação deve ter caráter de redimensionamento da ação pedagógica.

Nesse sentido, destacamos como desafios o desenvolvimento de pesquisas com temáticas a respeito da não democratização do Ensino Fundamental e de processos adotados para a ampliação, estabelecendo uma relação entre educação e sociedade.

Considerando a necessidade de acompanhamento, monitoramento e avaliação específicos para a implementação do Ensino Fundamental de nove anos em todos os sistemas e redes de ensino, destacamos também a urgência dessa medida junto aos municípios brasileiros, especialmente os mais pobres. Defendemos a ideia de que a nação inicia-se pelos territórios municipais.

\section{Referências}

ARELARO, L. R. G.; JACOMINI, M. A.; KLEIN, S. B. O ensino fundamental de nove anos e o direito à educação. Revista Educação e Pesquisa, v.37, n.1, São Paulo. jan./ abr. 2011.

ARELARO, L. R. G., O ensino fundamental no Brasil: avanços, perplexidades e tendências. Educ. Soc., Campinas, v.26, n.92, p.1039-66, Especial - Out. 2005.

BRASIL. Lei n.12.796, de 4 de abril de 2013. Altera a Lei n.9.394, para dispor sobre a formação dos profissionais da educação e dar outras providências. Brasília, DF, 2013a. Disponível em: <http://www.prolei. gov.br $>$. Acesso em: 30 abr. 13.

Ministério da Educação. Pacto Nacional pela Alfabetização na Idade Certa: o Brasil do futuro com o começo que ele merece. Brasília, DF, 2013b. Disponível em: $<$ http://www.mec. gov.br>. Acesso em: 30 abr. 13.

Ministério da Educação. Portaria $\mathbf{n}^{\circ}$ 867, de 4 de Julho de 2012. Institui o Pacto Nacional pela Alfabetização na Idade Certa e as ações do Pacto e define suas diretrizes gerais. Brasília, DF, 2012a. Disponível em: $<$ http://www.prolei. gov.br>. Acesso em: 30 abr. 13.

Presidência de República. Medi-

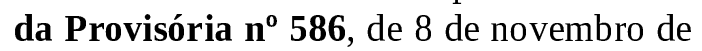
2012. Dispõe sobre o apoio técnico e financeiro da União aos entes federados no âmbito do Pacto Nacional pela Alfabetização na Idade Certa, e dá outras providências. Brasília, DF. 2012b. Disponível em: <http://www. prolei. gov.br>. Acesso em: 30 abr. 2013.

Conselho Nacional de Educação. Câmara de Educação Básica. Resolução n.06. Diretrizes Curriculares Nacionais para o Ensino Fundamental de Nove Anos. Brasília, DF, 2010a. Disponível em: <www.mec/ cne.gov.br>. Acesso em: 12 nov. 2012.

Resolução n.01.

Brasília, DF, 2010c. Disponível em: <www. mec/cne.gov.br>. Acesso em: 12 nov. 2012.

Resolução n.06.

Brasília, DF, 2010d. Disponível em: <www. mec/cne.gov.br>. Acesso em: 12 nov. 2012.

Resolução n.07. Brasília, DF, 2010e. Disponível em: <www. mec/cne.gov.br>. Acesso em: 12 nov. 2012. 
Senado Federal. Projeto de Lei de Plano Nacional de Educação n.8.035. Brasília, DF, 2010b. Disponível em: <www. mec/cne.gov.br>. Acesso em: 12 nov. 2012.

.Emenda Constitucional n.59.

Brasília, DF, 2009a. Disponível em: <www.planalto.gov.br>. Acesso em: 12 nov. 2012.

. Conselho Nacional de Educação. Câmara de Educação Básica. Resolução n. 05. Brasília, DF, 2009b. Disponível em: <www. mec/cne.gov.br>. Acesso em: 12 nov. 2012.

. Ministério da Educação. Secretaria de Educação Básica. Ensino Fundamental de Nove Anos: passo a passo do processo de implantação. Brasília, DF, 2009c. Disponível em: <www.mec.gov.br>. Acesso em: 12 nov. 2012.

Ensino Funda-

mental de nove anos: passo a passo do processo de implantação. 2.ed., set. 2009. Brasília, DF, 2009d. Disponível em: <www.mec. gov.br>. Acesso em: 12 nov. 2012.

A criança de 6

anos, a linguagem escrita e o ensino fundamental de nove anos: orientações para o trabalho com a linguagem escrita em turmas de crianças de 6 anos de idade. Brasília, DF, 2009e. Disponível em: <www.mec.gov.br>. Acesso em: 12 nov. 2012.

Conselho Nacional de Educação. Câmara de Educação Básica. Parecer n.4, de 20 de fevereiro de 2008. Orientação sobre os três anos iniciais do Ensino Fundamental de nove anos. Brasília, DF, 2008a. Disponível em: <http://www.mec/cne. gov.br>. Acesso em: 30 abr. 2013.

Ministério da Educação. Secretaria de Educação Básica. Indagações sobre Currículo. Brasília, DF, 2008b. Disponível em: <www. mec.gov.br>. Acesso em: 12 nov. 2012.
Conselho Nacional de Educação. Câmara de Educação Básica. Parecer n.05. Brasília, DF, 2007a. Disponível em: <www. mec/cne.gov.br>. Acesso em: 12 nov. 2012.

Parecer n.07.

Brasília, DF, 2007b. Disponível em: <www. mec/cne.gov.br>. Acesso em: 12 nov. 2012.

Parecer n.21.

Brasília, DF, 2007c. Disponível em: <www. mec/cne.gov.br>. Acesso em: 12 nov. 2012.

Lei n.11.274, de 6 de fevereiro de 2006. Altera a LDB n.9.394/96 dispondo sobre a duração de nove anos para o Ensino Fundamental, com matrícula obrigatória a partir dos 6 anos de idade. Brasília, DF, 2006a. Disponível em: <http://www.prolei. gov.br>. Acesso em: 11 out. 2012.

Senado Federal. Emenda Constitucional n.53. Brasília, DF, 2006b. Disponível em: <http://www.planalto. gov.br>. Acesso em: 11 out. 2012.

Conselho Nacional de Educação. Câmara de Educação Básica. Parecer n.39. Brasília, DF, 2006c. Disponível em: <www. mec/cne.gov.br>. Acesso em: 12 nov. 2012.

Parecer n.41.

Brasília, DF, 2006d. Disponível em: <www. mec/cne.gov.br>. Acesso em: 12 nov. 2012.

Parecer n.45.

Brasília, DF, 2006e. Disponível em: <www. mec/cne.gov.br>. Acesso em: 12 nov. 2012.

Ministério da Educação. Secretaria de Educação Básica. Terceiro Relatório do Programa: ampliação do ensino fundamental para nove anos. Brasília, DF, 2006f. Disponível em: <www.mec.gov.br>. Acesso em: 12 nov. 2012.

Ensino Funda-

mental de nove anos: orientações para a inclusão da criança de seis anos de idade. 
Brasília, DF, 2006g. Disponível em: <www. mec.gov.br>. Acesso em: 12 nov. 2012.

Lei n.11.114, de 16 de maio de 2005. Altera a LDB n.9.394/96 com o objetivo de tornar obrigatório o início do ensino fundamental aos seis anos de idade. Brasília, DF, 2005a. Disponível em: <http://www.prolei. gov.br>. Acesso em: 12 nov. 2012.

. Conselho Nacional de Educação. Câmara de Educação Básica. Parecer n.6. Brasília, DF, 2005b. Disponível em: <www. mec/cne.gov.br>. Acesso em: 11 nov. 2012.

Parecer n.18.

Brasília, DF, 2005c. Disponível em: <www. mec/cne.gov.br>. Acesso em: 11 nov. 2012.

Indicação n.3.

Brasília, DF, 2005d. Disponível em: <www. mec/cne.gov.br>. Acesso em: 11 nov. 2012.

Resolução n.3.

Brasília, DF, 2005e. Disponível em: <www. mec/cne.gov.br>. Acesso em: 11 nov. 2012.

. Ministério da Educação. Secretaria de Educação Básica. Segundo Relatório do Programa: ampliação do ensino fundamental para nove anos. Brasília, DF, $2005 f$. Disponível em: <www.mec.gov.br>. Acesso em: 11 nov. 2012.

Orientações Ge-

rais: Ensino Fundamental de nove anos. Brasília, DF, 2004a. Disponível em: <www. mec.gov.br>. Acesso em: 11 nov. 2012.

Primeiro Rela-

tório do Programa: ampliação do ensino fundamental para nove anos. Brasília, DF, 2004b. Disponível em: www.mec.gov.br. Acesso em: 11 nov. 2012.

Conselho Nacional de Educação. Câmara de Educação Básica. Parecer n.24. Brasília, DF, 2004c. Disponível em: www. mec/cne.gov.br. Acesso em: 11 nov. 2012.
Lei $\mathbf{n}^{\circ}$ 10.172, de 9 de janeiro de 2001. Institui o Plano Nacional de Educação. Brasília, DF, 2001. Disponível em: <http:// www.prolei. gov.br>. Acesso em: 11 nov. 2012.

Conselho Nacional de Educação. Câmara de Educação Básica. Parecer n.20. Brasília, DF, 1998. Disponível em: <www. mec/cne.gov.br>. Acesso em: 11 nov. 2012.

Congresso Nacional. Lei n.9.394, de 20 de dezembro de 1996. Fixa Diretrizes e Bases da Educação Nacional e dá outras providências. Brasília, DF, 1996a. Disponível em: <http://www.prolei. gov.br > Acesso em: 30 abr. 2013.

Constituição da República Federativa do Brasil de 1988, de 5 de outubro de 1988. Brasília, DF. 1988. Disponível em: <http://www.planalto.gov.br>. Acesso em: 30 abr. 2013.

GORNI, D. A. P.. Ensino Fundamental de 9 anos: estamos preparados para implantá-lo? Ensaio: aval. pol. públ. Educ., Rio de Janeiro, v.15, n.54, p. 67-80, jan./mar. 2007.

KOERNER, R. M.. Os professores e sua participação na implementação do Ensino Fundamental de 9 anos. Jornal de políticas educacionais, n.11, jan.-jun. 2012, p.12-22.

SANTOS, L. L. C. P.; VIEIRA, L. M. F. "Agora seu filho entra mais cedo na escola": a criança de seis anos no Ensino Fundamental de nove anos em Minas Gerais. Educ. Soc., Campinas, v.27, n.96 - Especial, p.775-96, out. 2006.

SAVELI, E. L.. Ensino Fundamental de nove anos: bases legais de sua implantação. Práxis Educativa, Ponta Grossa, PR, v.3, n.1, p.67-72, jan.-jun. 2008.

SILVA, A. A.; SCAFF, E. A. S.. Ensino Fundamental de nove anos: política de integração ou de conformação social? Práxis 
Educativa, Ponta Grossa, v.5, n.1, p. 97107, jan.-jun. 2010.

SILVA, R. da. A implementação do Ensino Fundamental de nove anos e seus efeitos para a educação infantil: um estudo em municípios catarinenses. 2009. Dissertação (Mestrado em Educação). Centro de Ciências da Educação. Programa de Pós-graduação em Educação. Universidade Federal de Santa Catarina.

SOUZA, K. R.. A reorganização do ensino fundamental de nove anos a partir do projeto político pedagógico das escolas. 2012. Dissertação (Mestrado em Educação). Faculdade de Educação, Universidade Federal da Grande Dourados, Dourados.

VIEIRA, S. L.; ALBUQUERQUE, M. G. M. Política e planejamento educacional. 3. ed. Fortaleza: Edições Demócrito Rocha, 2002.

Enviado em: 06/05/2013

Aceito em: 25/07/2013 